Article

\title{
Study on Heat Effect of High-Power Continuous Wave Laser on Steel Cylinder
}

\author{
Liu Yang ${ }^{1, *}$, Tang Wei ${ }^{1}$, Liu Lisheng ${ }^{1}$, Shao Junfeng ${ }^{1}$, Shao Ming ${ }^{2}$ and Cheng Xiangzheng ${ }^{2}$ \\ 1 State Key Laboratory of Laser Interaction with Matter, Changchun Institute of Optics, \\ Fine Mechanics and Physics, Chinese Academy of Sciences, 3888 Southeast Lake Road, Changchun 130033, \\ China; twei222@163.com (T.W.); liuls@ciomp.ac.cn (L.L.); 13159754836@163.com (S.J.) \\ 2 Key Laboratory of Electro-Optical Countermeasures Test \& Evaluation Technology, Luoyang 471003, China; \\ lyshaoming@163.com (S.M.); renxiaoyaocxz_1@163.com (C.X.) \\ * Correspondence: liuyangdk@ciomp.ac.cn
}

Received: 26 August 2020; Accepted: 3 November 2020; Published: 5 November 2020

check for updates

\begin{abstract}
This paper investigates the heat effects of continuous high-power lasers on steel cylinders. A theoretical model combining the mechanical characteristics and heat transfer of the steel cylinder that irradiated by a high-power laser is established. Simulations in temperature fields predict the varying heat effects on steel cylinders corresponding to different laser power levels, and more importantly, the thresholds of laser penetrations. The predictions are further validated by experimental tests, which use 1.5-2.8 kW laser irradiating on 7-15 mm thick steel cylinders. It has been found that the ablation mechanism of steel cylinder is primarily dependent on either the mass transfer of vaporized ablation or liquefied material under the action of vaporized back pressing. The present $0-300 \mathrm{~s}$ temperature field analyses show that steel melts at $1720 \mathrm{~K}$ and vaporizing ablation happens at $3250 \mathrm{~K}$. It has also been observed that in the contact region between the laser and steel cylinder, the melting and vaporization accompanied by the interaction of the ablation process are followed by the sharp splash phenomenon.
\end{abstract}

Keywords: laser-metal interaction; heat effect; steel cylinder; temperature field simulation; equivalent scaling law

\section{Introduction}

The last few decades have seen rapid development in high-power laser technology, and the laser-induced thermal and mechanical problems have received much attention [1]. From the perspective of laser-matter interaction, the laser with an energy density higher than $10^{3} \mathrm{~W} / \mathrm{cm}^{2}$ on the target is defined as a high-power laser, and otherwise is a low-power laser [2]. The mainstream researches have had a significant contribution to laser applications such as laser-based manufacturing, dynamic high-pressure issues in nuclear engineering, laser heat effect, and laser safety [3]. The heat effect of high-power lasers on solid materials is manifested by thermal effect and ablation-induced mechanical effect, exhibiting temperature rise, expansion, melting, vaporization, scattering, breakdown, and spallation [4].

Irradiation of varying laser power levels would cause different thermal stresses and thermal impacts correspondingly. In general, low-power lasers cause thermal-force coupling effects such as local temperature rise, thermal stress and even melting of the solid material targets; high-power lasers induce the target to generate plasma and cause high-amplitude shock waves yielding impact effects, and the anisotropic non-metallic material would show kinetic damages such as interlaminar cracking, superficial peeling, and cone-shaped perforation [4,5]. Huang et al. [6,7] established a similarity criterion equation of the steel cylinder with inner pressure under laser irradiation by using 
the similarity analysis theory and Finite Element Method (FEM). Boley et al. [8] experimented with a high-power laser beam directed onto thin aluminum sheets to demonstrate that airflow produces a strong enhancement of the interaction. According to the experiment, the airflow-induced pressure difference between front and rear faces causes the metal to bulge into the beam. Wang et al. [9] studied the heat effect of the pulse-pulse composited laser, which is composed of a microsecond and a nanosecond pulsed laser. It found that when only a long-pulse laser is applied, there was a partial melting trace on the surface of the 2024 aluminum alloy plate, and when only a short-pulse laser is applied, the surface of the aluminum plate had obvious melting marks. Under the composited laser, the average power density of the facula area on the target surface is about the arithmetic superposition of the long-pulse laser and short-pulse laser, and the surface melting is stronger than that of single long-pulse laser applied. It remarked that the increment of the heat effect on the target is the result of the increasing of the laser power density. Liu et al. [10] has carried out research on the damage effect of the composite laser on the flat window. According to the experimental results, the composite laser can effectively reduce the damage threshold of the flat window. Osterholz et al. [11] irradiated metal samples with a continuous wave $(\mathrm{CW})$ laser beam at a power of $1 \mathrm{~kW}$ and a wavelength of $1.07 \mu \mathrm{m}$. Using high-speed video sequences yields expansion velocities of the vapor plume of samples. The experiment results indicate that the metal vapor is partially ionized and that there is a significant contribution of inverse bremsstrahlung to the absorption of laser energy in the partially ionized vapor plume. Horak et al. [12] experimentally studied the thermodynamics process of steel sheets irradiated by a $1.07 \mu \mathrm{m}$ laser using a non-contact measuring method. Based on the experimental results, a criterion for the onset of the perforation explaining the observed local minimum in the perforation time versus beam radius curve is presented. Xiao et al. [13] simulated the composite laser irradiation on aluminum sheet. A finite element method was purposed to model the thermodynamic characteristics of aluminum sheet irradiated by a composite laser, which is coaxially combined by a $1064 \mathrm{~nm}$ pulse laser and a $1064 \mathrm{~nm}$ continuous laser. The result has shown an increment of the molten metal zone (also known as molten pool) and spot center temperature as the spot radius decreases. Some other researchers have studied the effects of laser parameters on laser irradiation effects $[14,15]$. There are also several other studies focusing on the effects of flow field environment on damage. According to the research results of related literatures [16-20], the influence of the change of convective heat transfer coefficient on laser irradiated metal target is limited in low velocity flow fields.

Through the analysis of the above literature, we can see that the laser irradiation effect is mainly divided into low-power and high-power lasers. The experimental and simulation methods are the main research methods. To the best of the authors' knowledge, the flat metal plates were selected as the laser target in most previous studies. The present research focuses on the thermal damage process of a steel cylinder irradiated by a CW laser, in a combination of Multiphysics coupling simulations by the finite element method and experimental tests.

\section{Equivalent Thermodynamic Model}

\subsection{Mechanical Equivalence}

To study the heat effect of high-power lasers and associated failure modes of targets, it commonly requires time-consuming and very expensive tests on the prototype structures [21,22]. In contrast, the present study adopts the equivalent scaling experiments, which reduce the cost and risk of the tests, while also maintaining accuracy. By establishing an equivalent scaling model, the simulation test parameters can be quickly and clearly defined [22]. The similarity criterion is a dimensionless invariant which can be expressed by $\prod_{i}$. To ensure that the equivalent scaling model has the same mechanical characteristics as the original target, the similarity criteria are:

1. The equivalent scaling model has identical material properties to the prototype structure:

$$
\Pi_{1}=\sigma_{\theta 0}=\sigma_{\theta 1}
$$


where $\sigma$ is the yield stress of material; subscript 0 represents the prototype structure and subscript 1 is for the equivalent model.

2. The internal and external stress conditions of the prototype and the equivalent model are equal:

$$
\Pi_{2}=\frac{D_{0}}{\delta_{0}}=\frac{D_{1}}{\delta_{1}}
$$

where $D$ is the cylinder diameter and $\delta$ is the cylinder shell thickness.

3. The identity heat transfer speed through the cylinder thickness directions:

$$
\frac{2\left(\kappa_{0} t_{0}\right)^{\frac{1}{2}}}{\delta_{0}}=\frac{2\left(\kappa_{1} t_{1}\right)^{\frac{1}{2}}}{\delta_{1}}
$$

where $\kappa$ is the thermal diffusivity, $t$ is the irradiation time.

$$
\Pi_{3}=\frac{t_{1}}{t_{0}}=\left(\frac{\delta_{1}}{\delta_{0}}\right)^{2}
$$

4. During the irradiation period $t$, the energy density of laser absorbed by the per unit thickness material should be equal:

$$
\frac{a_{0} q_{\text {inc } 0} t_{0}}{\delta_{0}}=\frac{a_{1} q_{\text {inc1 } 1} t_{1}}{\delta_{1}}
$$

where $a$ is energy absorption rate and $q_{\text {inc }}$ is incident laser power density.

$$
\Pi_{4}==\frac{A_{1} q_{\text {inc1 }}}{A_{0} q_{\text {inc } 0}}=\frac{\delta_{1}}{\delta_{0}} \frac{t_{0}}{t_{1}}
$$

5. The length $L$ of the cylinders should be long enough that the influence of the boundary conditions at both ends on the spot areas are negligible:

$$
\Pi_{5}=\frac{L_{1}}{L_{0}}=\frac{\sqrt{D_{1} \delta_{1}}}{\sqrt{D_{0} \delta_{0}}}
$$

6. The center angle of the targets corresponding to the spot diameter should be equal:

$$
\Pi_{6}=\frac{d_{z 1}}{d_{z 0}}=\frac{D_{1}}{D_{0}}
$$

By satisfying the above conditions, the mechanical properties of the prototype structures could be treated as the same before and after the equivalent scaling.

\subsection{Equivalence of Heat Transfer}

The coupling of material mechanical characteristics and heat transfer subjected to laser irradiation constitutes the thermoelastic model, which ignores the inertial force and applies the quasi-static condition for solving the temperature field. It assumes that the laser energy is absorbed by the surface of the target, and the absorption of the substrate is negligible [23-26]. Therefore, the absorption of the laser energy is treated as a heat source on the target surface to solve the heat conduction equation inside the target. From the above conditions, the control equation of the thermal response and the solution conditions of the target under laser irradiation are as follows:

Boundary condition

$$
-\left.k \frac{\partial T}{\partial n}\right|_{\Sigma_{1}}=\alpha I-h T
$$




$$
-\left.k \frac{\partial T}{\partial n}\right|_{\Sigma_{2}}=-h T
$$

where $\alpha$ is the laser absorptivity of materials; $h$ is the convective heat transfer coefficient; $k$ is the thermal conductivity; $I$ is the laser power density; $\Sigma_{1}$ is the laser irradiation surface; $\Sigma_{2}$ is the non-laser irradiation surface; $n$ is the normal coordinate of laser incident plane.

If the prototype structure's variable $y$ is $y_{1}$, the similitude model variable $y$ is $y_{2}$, and assuming the similarity multiple is $C_{y}$, then

$$
c_{y} y_{1}=y_{2}
$$

Similar transformation of the heat conduction equation can be obtained

$$
\rho C_{p} \frac{c_{T} \partial T_{1}}{c_{t} \partial t_{1}}-k \frac{c_{T}}{c_{L}^{2}} \nabla^{2} T_{1}=0
$$

Taking similar indicators

$$
\frac{c_{t}}{c_{L}^{2}}=1
$$

Equation (9) becomes

$$
-\left.k \frac{c_{T}}{c_{L}} \frac{\partial T}{\partial n}\right|_{\Sigma_{1}}=\alpha c_{I} I-h c_{T} T
$$

Get similar indicators

$$
\frac{c_{T}}{c_{L}}=c_{I} \text { and } \frac{c_{T}}{c_{L}}=c_{T}
$$

Similar transformation of Gaussian distributed heat source power density model

$$
I_{2}=\frac{c_{x} P_{1}}{\pi c_{L}^{2} R_{0}^{2}} \exp \left(-\frac{c_{L}^{2} x_{1}^{2}+c_{L}^{2} y_{1}^{2}}{c_{L}^{2} R_{0}^{2}}\right)=\frac{c_{x}}{c_{L}^{2}} I_{1}
$$

where $I$ is the laser power density; $P$ is the laser power; $R_{0}$ is the laser spot radius.

Combined with Equation (15)

$$
c_{\mathrm{X}}=c_{T} \cdot c_{L}
$$

Since the focus of the present paper is on the thermal response of the cylinder, the temperature field similarity coefficient is set to 1 . The scale rate of the thermal response of the laser irradiated cylinder is shown in Table 1. It can be seen that the prototype cylinder test data that exceeds existing test conditions can be obtained by scaling parameters such as laser power, spot size, effector size thickness, and irradiation time.

Table 1. Similitude Rate of Thermal Response for Target under Laser Irradiation.

\begin{tabular}{ccccccc}
\hline & Laser Power & Spot Size & Power Density & Target Thickness & Time & Temperature \\
\hline Scale rate & $C_{x}$ & $C_{x}$ & $1 / C_{x}$ & $C_{x}$ & $C_{x}{ }^{2}$ & 1 \\
\hline
\end{tabular}

\section{Heat Effect on Steel Cylinder}

\subsection{Numerical Simulation}

Select $1.06 \pm 0.02 \mu \mathrm{m}$ Nd-YAG fiber lasers were the laser source for simulation. The Nd-YAG fiber laser is widely used in manufacturing because of its good beam quality and low cost. Moreover, the metal material has a high laser absorption rate for this wavelength. Due to the complexity of the laser ablation mechanism, research on laser ablation models is still insufficient. Although commercial Finite Element Analysis software adapts the deformation grid method or the element birth and death method, their methods can only simulate surface phenomena and have nothing to do with the ablation 
mechanism. Therefore, the simulation model in this paper does not embrace the material removal. Transient simulation of laser ablation steel cylinders used COMSOL Multiphysics (COMSOL Inc., Burlington, MA, USA). The cylinder model was established based on the similitude rate of Table 1. The numerical model of the steel cylinder was established at the scaling ratio $1 / 4$ steel cylinder with symmetric boundary conditions. The laser was directly irradiated on the front surface of the cylinder. The incident laser power density followed Gaussian distribution. The power density distribution is shown in Figure 1 (taking $2.4 \mathrm{~kW}$ as an example, the distribution of other power densities is similar), and the key parameters for the simulation are given in Table 2. [2,27]. The temperature field was solved by the transient solver with irradiation time of $0-300 \mathrm{~s}$.

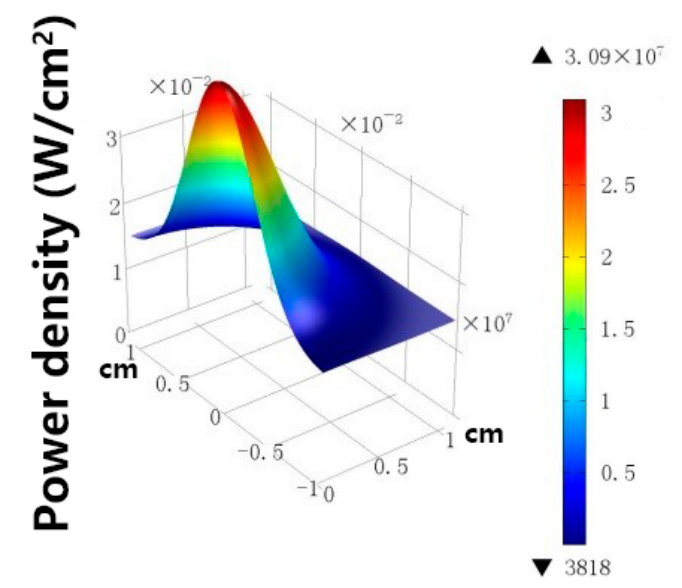

Figure 1. Schematic diagram of $2.4 \mathrm{~kW}$ incident laser power density distribution at $10 \mathrm{~mm}$ spot diameter.

Table 2. Loading conditions for simulation.

\begin{tabular}{cc}
\hline Parameter & Value \\
\hline Laser power $[\mathrm{kW}]$ & $1.5,2.0,2.4,2.8$ \\
Laser wavelength $[\mu \mathrm{m}]$ & $1.06 \pm 0.02$ \\
Laser spot radius $[\mathrm{mm}]$ & 10,20 \\
Target thickness $[\mathrm{mm}]$ & $15,13,9,7$ \\
Latent heat of vaporization $[\mathrm{J} / \mathrm{g}]$ & 6430 \\
Melting latent heat $[\mathrm{J} / \mathrm{g}]$ & 247 \\
Melting temperature $[\mathrm{K}]$ & 1670 \\
Initial temperature $[\mathrm{K}]$ & 273,300 \\
Irradiation time $[\mathrm{s}]$ & 10 \\
\hline
\end{tabular}

\subsection{Influence of Laser Spot Radius on Heat Effect}

Figure 2 reveals the thermal responses of the $15 \mathrm{~mm}$ thickness steel cylinder subjected to different power density lasers. Continuous laser irradiations on targets were at the power of $1.5 \mathrm{~kW}, 2.0 \mathrm{~kW}$, $2.4 \mathrm{~kW}$, and $2.8 \mathrm{~kW}$, respectively, with the laser spot diameter of $10 \mathrm{~mm}$. The simulation results within $300 \mathrm{~s}$ of the front surface spot center temperature and the corresponding inner surface center temperature are shown in Figure 3.

For comparison, simulation results of the lasers with a spot diameter of $20 \mathrm{~mm}$ at the same power levels are shown in Figure 4.

For the simulation result of a $20 \mathrm{~mm}$ diameter laser spot, the temperature of the front surface does not exceed $3250 \mathrm{~K}$ within $300 \mathrm{~s}$, and there is no vaporization ablation. Under the laser power of 1.5 to $2.8 \mathrm{~kW}$, the front surface temperature exceeds $1720 \mathrm{~K}$, and a certain depth of molten ablation forms on the surface of the steel cylinder. However, the temperature of the back surface does not exceed $1720 \mathrm{~K}$, which means the steel cylinder cannot be penetrated within $300 \mathrm{~s}$. Comparing the temperature 
distribution in Figures 4 and 5, it can be seen that when the laser power is greater than $2.8 \mathrm{~kW}$ and the laser spot diameter is less than $10 \mathrm{~mm}$, the steel cylinder $(15 \mathrm{~mm})$ can be penetrated within $272.2 \mathrm{~s}$. The melting-through mechanism of this process is that the steel cylinder forms through holes under the action of vaporization back pressing.

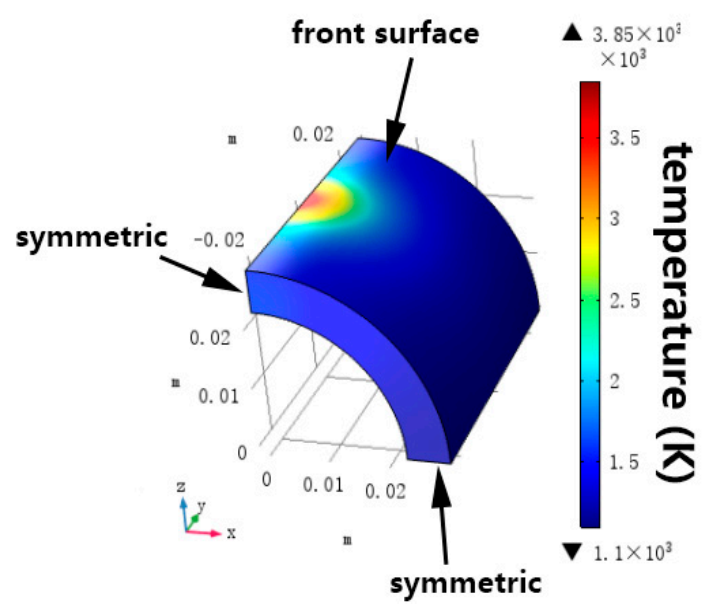

Figure 2. Temperature distribution on $15 \mathrm{~mm}$ thickness cylinder subjected to $2.4 \mathrm{~kW}$ incident laser with spot diameter of $10 \mathrm{~mm}$.

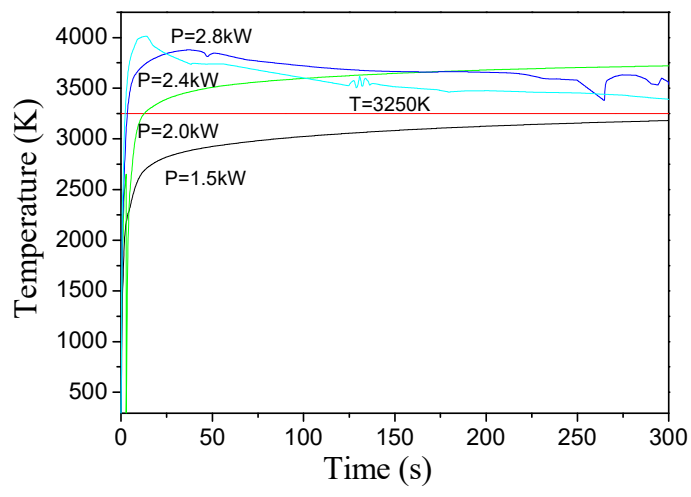

(a)

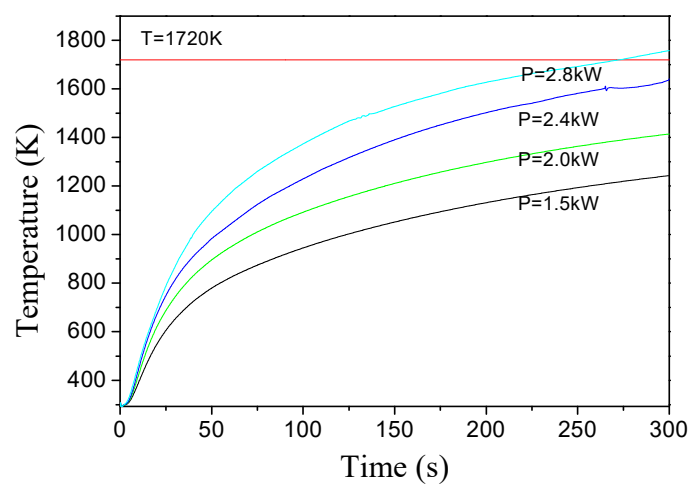

(b)

Figure 3. Center temperature of front and back surface of the steel cylinder under 1.5 2.8 kW laser power. (a) Front surface, (b) Back surface. 


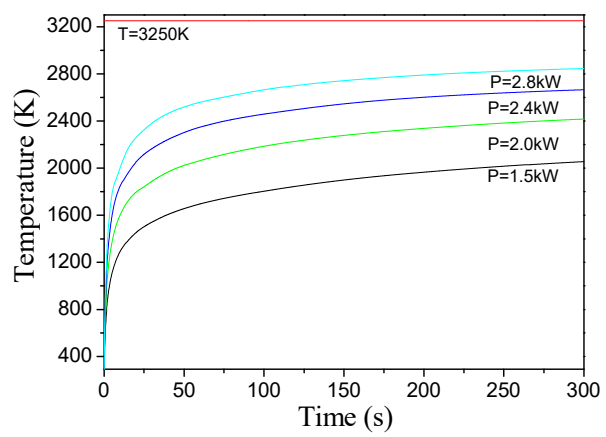

(a)

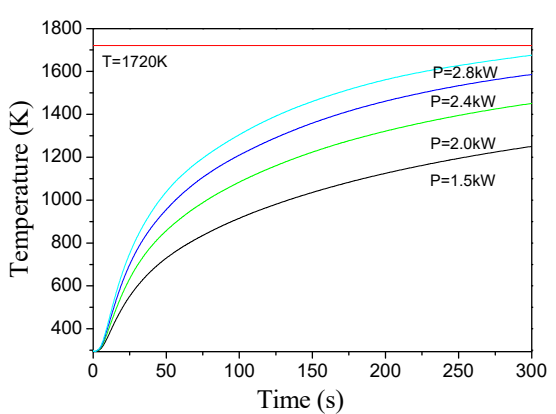

(b)

Figure 4. Center temperature of front and back surface of the steel cylinder under $20 \mathrm{~mm}$ laser spot diameter. (a) Front surface, (b) Back surface.

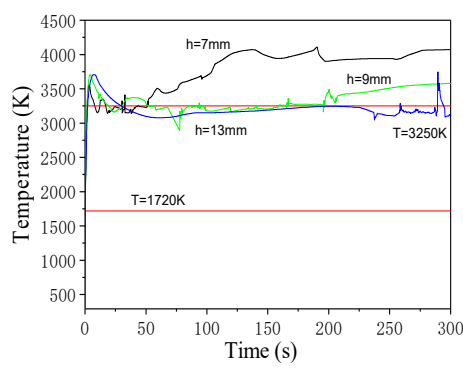

(a)

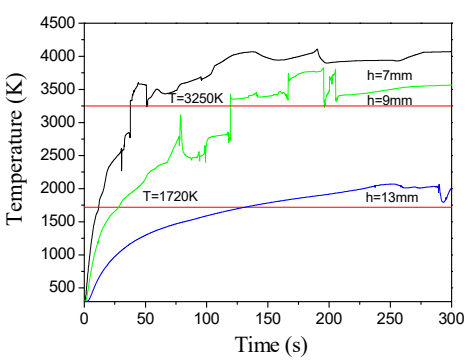

(b)

Figure 5. Center temperature of front and back surface of the steel cylinder under cylinder thickness 7-13 mm. (a) Front surface, (b) Back surface.

\subsection{Influence of Cylinder Thickness on Heat Effect}

Set the laser spot diameter to $10 \mathrm{~mm}$ and the irradiation time $300 \mathrm{~s}$ as simulation conditions. The temperature change during irradiation on the 7, 9, and $13 \mathrm{~mm}$-thick cylinders is shown in Figure 5 .

The temperature of the front surface of the cylinder rapidly rose to above $3250 \mathrm{~K}$ under the irradiation of a laser with a spot diameter of $10 \mathrm{~mm}$ at laser power of $2.8 \mathrm{~kW}$. Under the same conditions, the cylinder of 7,9 and $13 \mathrm{~mm}$ thick vaporized and ablated at 1.6, 1.8 and $2.2 \mathrm{~s}$, respectively. The center temperature of the cylinder back surface exceeded $1720 \mathrm{~K}$ in $11.2,28.2$ and $131.2 \mathrm{~s}$, respectively. It revealed that the laser could penetrate through the cylinder under the melt-through mechanism, and the through-hole was formed under the action of vaporization and back-punching. The $7 \mathrm{~mm}$ cylinder was melted through at $37.7 \mathrm{~s}$, and there might have been a vaporization burn-through.

The curves of the front surface center temperature and the corresponding back surface center temperature for the $20 \mathrm{~mm}$ laser spot diameter are shown in Figure 6. Subjected to the laser power of 
$2.8 \mathrm{~kW}$ and a spot diameter of $20 \mathrm{~mm}$, the front surface temperatures of the 7,9 mm and $13 \mathrm{~mm}$-thick cylinder did not exceed $3250 \mathrm{~K}$ within $300 \mathrm{~s}$, so there was no vaporization ablation. Because of melt ablation, the front surface center temperatures exceeded $1720 \mathrm{~K}$ at $4.2,4.5$ and $4.7 \mathrm{~s}$, respectively. The back-surface center temperatures were $23.5,50.2$ and $195.8 \mathrm{~s}$ when over $1720 \mathrm{~K}$. This means that the cylinders were burned through, and the burn-through mechanism was that the material melted to form a through-hole.

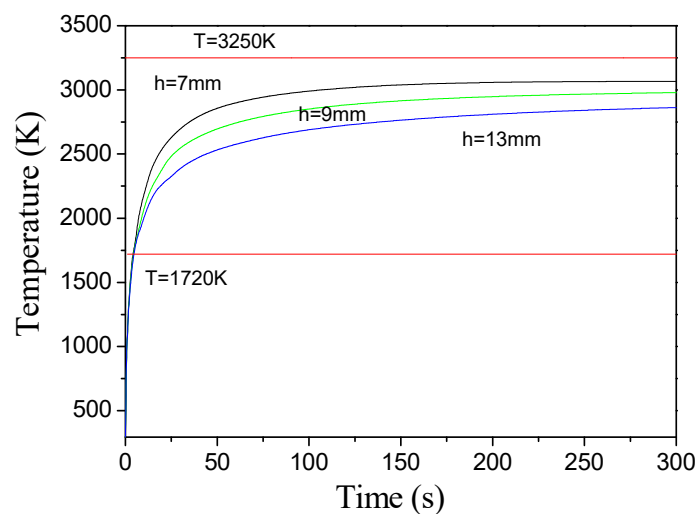

(a)

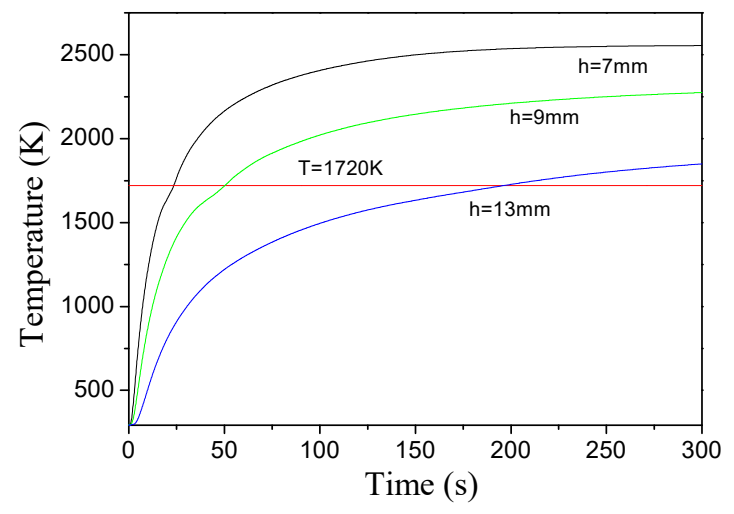

(b)

Figure 6. Center temperature of front and back surface of the steel cylinder under the spot diameter of $20 \mathrm{~mm}$. (a) Front surface, (b) Back surface.

Through the temperature change simulation, it was found that under the action of a small laser spot (10 mm diameter), the front surface of the cylinder with a thickness less than $13 \mathrm{~mm}$ rapidly undergoes a vaporization phase change within $2.2 \mathrm{~s}$, the cylinder is burnt through within $131.2 \mathrm{~s}$, and the burn-through mechanisms are vaporization and burn-through. When subjected to a large spot laser (diameter $20 \mathrm{~mm}$ ), the cylinder with a thickness of $13 \mathrm{~mm}$ or less does not undergo vaporization and ablation, and the surface melts only after $195.8 \mathrm{~s}$. Therefore, the mechanism of the burn-through is caused by heat fusion to form a through-hole in the cylinder.

\subsection{Experimental Tests}

A laser and solid material interaction test platform was established (Figure 7) to test the heat effect of the high-power laser and to verify the simulation results. The laser used in the experiment was a $1080 \mathrm{~nm}$ Nd-YGA fiber laser with the maximum output power $3.5 \mathrm{~kW}$ and beam quality $\mathrm{M}^{2} \leq 1.8$. The steel cylinders were tested with lasers power of 2 and $2.4 \mathrm{~kW}$ and laser spot diameters of 15 and $20 \mathrm{~mm}$, respectively. The temperature fluctuations on the back surface of the steel cylinder recorded by thermal imagers are shown in Figure 8. It can be seen that the temperature rise curves of the experiment and simulation are in good agreement, which verifies the accuracy of the previous simulations.

The tests were carried out by increasing the power up to $2.8 \mathrm{~kW}$ and the spot diameter constantly at $10 \mathrm{~mm}$, and the test processes were recorded by a high-speed camera with attenuator before it. The absorption of laser energy in the cylinder caused internal heat conduction, resulting in a temperature gradient inside. When the temperature reached the melting point, the energy continued to accumulate and the steal melted after a melting-latent heat, which caused a short "smooth" segment in the temperature rise curve, and then the temperature continued. As the laser continued to act, the temperature continued to rise and eventually reached thermal equilibrium and tended to stabilize.

Under high-power laser irradiation, mass migration is due to laser melting and vaporization. The laser-introduced combustion waves and detonation waves result in extremely high ablation pressure and temperature inside the cylinder to a molten state and even severe splashing of metal ablates in the melting state. At the beginning of ablation, the direct interaction zone of the front surface forms a small molten pool due to the continuous temperature rise. As the test continues, the 
"keyhole" perforation begins to appear in the center of the weld pool, and the perforation of the weld pool on the front surface increases rapidly before the cylinder is penetrated. At this point, the back surface appears to collapse significantly (as shown in Figure 9) as the laser continues to load and the cylinder is penetrated. The thermal response process of the cylinder is basically consistent with the simulation result of Figure 6. The front surface begins to melt within $30 \mathrm{~s}$, the melting zone is continuously enlarged, and the molten pool is formed at the back surface at $125 \mathrm{~s}$. The entire cylinder is melts through in about $250 \mathrm{~s}$. We believe that the deviation between the experimental data and the simulation data mainly comes from the following aspects: firstly, the selective omitting of the boundary conditions by the equivalent scaling model itself, and secondly, by the uncertainty in the experimental process. According to the experimental phenomena, it can be seen that the process of damage is similar to that of simulation. During the interaction between the laser and the steel cylinder, both the penetration and the vaporization exist simultaneously. The gasification at the center of the molten pool causes the needle-like perforation and the collapse of the inner surface.

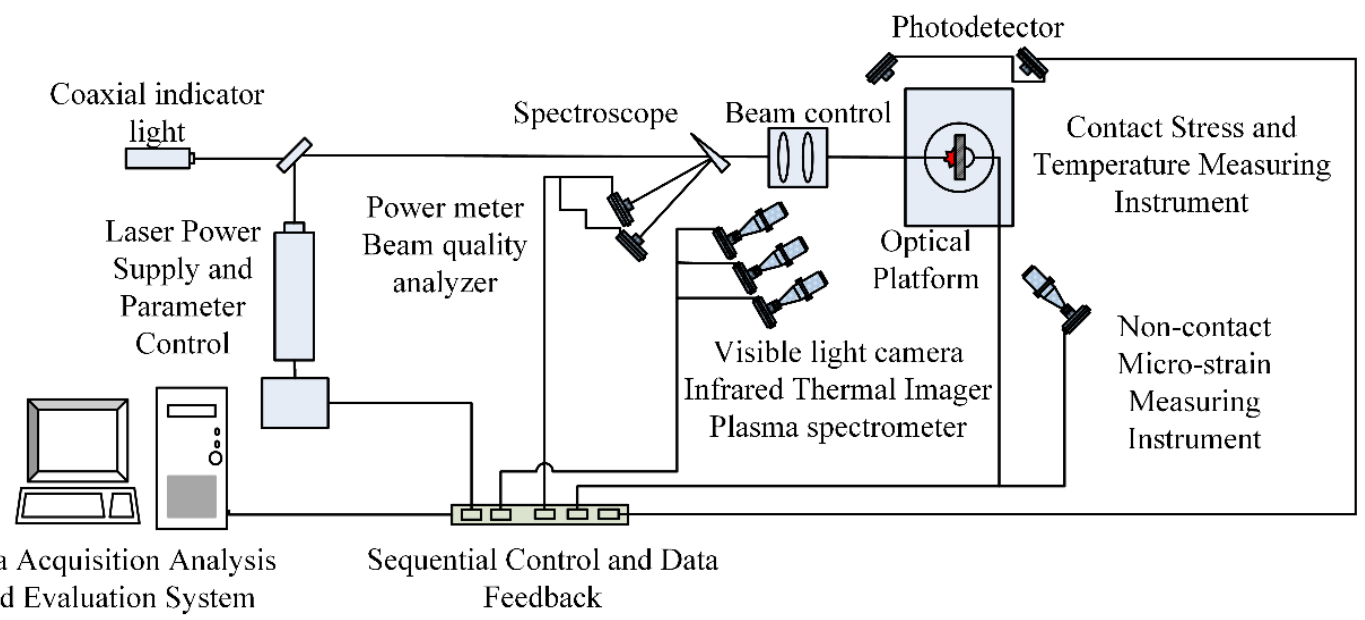

Figure 7. Schematic diagram of the experimental platform.

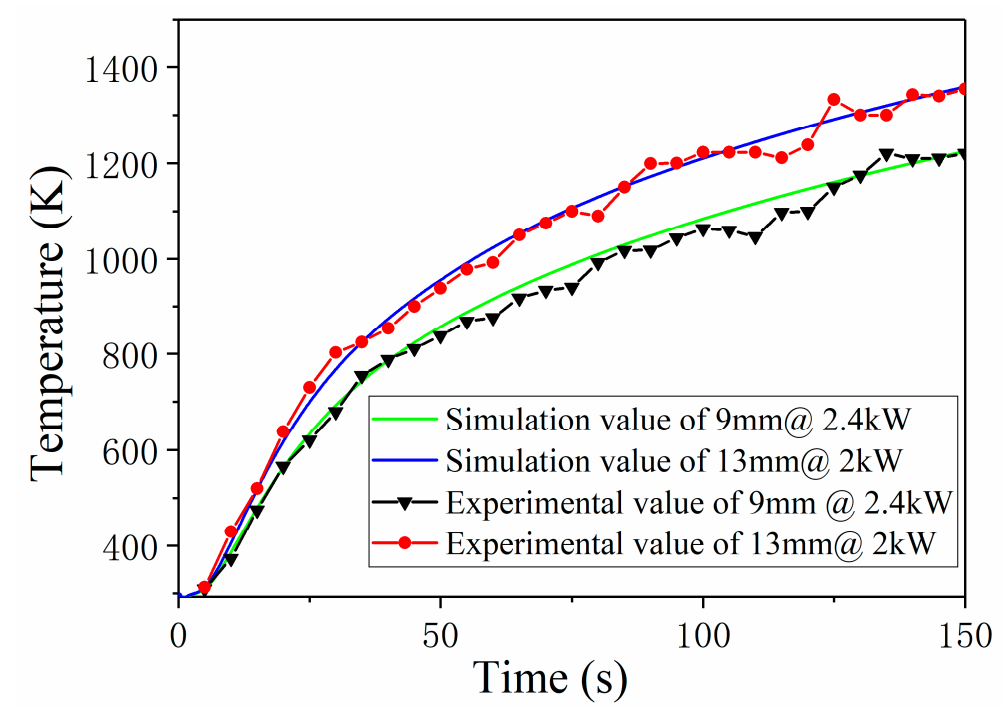

Figure 8. Comparison of temperature development curve predicted by Finite element model against the experimental results, where the incident lasers are at 2.0 and $2.4 \mathrm{~kW}$ and the cylinders are with 9 and $13 \mathrm{~mm}$ thick, respectively. 


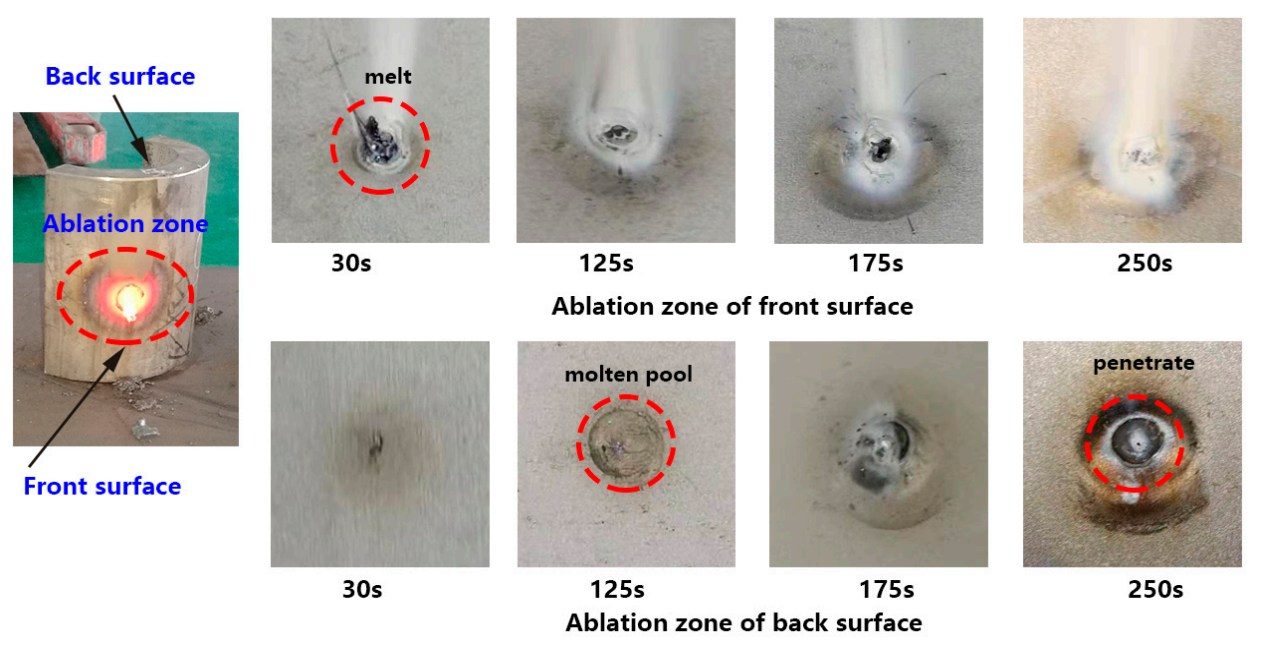

Figure 9. Damage phenomenon of the front and back surfaces of the steel cylinder (cylinder thickness: $13 \mathrm{~mm}$, spot diameter: $10 \mathrm{~mm}$, laser power: $2.8 \mathrm{~kW}$ ).

\section{Conclusions}

The paper investigates damage effects of a steel cylinder irradiated by a high-power CW laser beam. We obtained the following conclusions by observing the damage phenomenon:

1. For a $15 \mathrm{~mm}$-thick steel cylinder, when the laser power is greater than $2.8 \mathrm{~kW}$ and the spot diameter is smaller than $10 \mathrm{~mm}$, the penetration can be achieved within $300 \mathrm{~s}$. For a cylinder with the thickness of 7 to $13 \mathrm{~mm}$, the penetration can be achieved within $131.2 \mathrm{~s}$, under the action of a laser with a spot diameter of $10 \mathrm{~mm}$ and power of $2.8 \mathrm{~kW}$. The penetration mechanism is a through-hole formed by the vaporization and back stamping.

2. For the cylinder of 7 13 mm thickness, the penetration can be achieved within $195.8 \mathrm{~s}$ under the action of the spot diameter of $20 \mathrm{~mm}$ and power of $2.8 \mathrm{~kW}$. In this case, the burn-through mechanism is that the heat is melted to cause the cylinder to form a through-hole.

3. The interaction zone between the steel cylinder and the laser produces a violent melting and vaporization process, and the laser-maintained combustion wave and detonation wave appear, and the splashing phenomenon occurs in the interaction area of the ablation process.

Author Contributions: L.Y. and L.L. wrote the original draft. T.W. and S.J. are responsible for collating experimental data. S.M. and C.X. provided resource support for the research. All authors have read and agreed to the published version of the manuscript.

Funding: The work reported in this paper is supported by the National Key Laboratory of laser matter interaction (Grant No. SKLLIM1904) and the National open project (Grant No. GKCP2018001) and "Xuguang" Talent Program of Changchun Institute of Optics and Machinery, Chinese Academy of Sciences (Grant No. 201900X).

Conflicts of Interest: The authors declare no conflict of interest.

\section{References}

1. Sun, A.; Cheng, C.; Du, Z. Thermal damage of aluminum honeycomb panel irradiated by continuous laser. Optik 2018, 12, 131-138. [CrossRef]

2. Mulser, P.; Bauer, D. High Power Laser-Matter Interaction; Springer: Berlin/Heidelberg, Germany, 2010.

3. Hege, C.S.; Muller, O.; Merlat, L. Laser protection with optical limiting by combination of polymers with dyes. J. Appl. Polym. Sci. 2019, 136, 47150. [CrossRef]

4. Allmen, M.; Blatter, A. Laser-Beam Interactions with Materials: Physical Principles and Applications; Springer: Berlin/Heidelberg, Germany, 1995.

5. Jacobs, P.-P.; Nelsen, B.; Taudt, C.; Rudek, F.; Hartmann, P. In-process monitoring of laser ablation on thin steel membranes by multispectral shape-from-shading. In Proceedings of the Photonic Instrumentation Engineering VI, San Francisco, CA, USA, 5-7 February 2019; p. 10925. 
6. Huang, C.-G.; Chen, S.-Y.; Duan, Z.-P. Similarity Criterion about Deformation and Failure of Pressurized Cylinder Subjected to Laser Irradiation. High Power Laser Part. Beams 2004, 8, 962-966.

7. Huang, C.-G.; Duan, Z.-P. Studies on the dynamic buckling of circular plate irradiated by laser beam. Appl. Math. Mech. 2002, 23, 748-754.

8. Boley, C.D.; Cutter, K.P.; Fochs, S.N.; Pax, P.H.; Rotter, M.D.; Rubenchik, A.M.; Yamamoto, R.M. Interaction of a high-power laser beam with metal sheets. J. Appl. Phys. 2010, 107, 043106. [CrossRef]

9. Wang, Q.; Pang, B.; Zhang, Y.; Hu, W.; Li, Z. Damage Mechanism of Aluminum by Long-Short Composite Pulsed Laser. Laser Optoelectron. Prog. 2018, 55, 101404. [CrossRef]

10. Yang, L.; Lisheng, L.; Wei, T.; Junfeng, S.; Xuelei, L.; Junjie, S.; Ming, S.; Xiangzheng, C. Experimental Study on the Damage of Optical Materials by Out of Band Composite Laser. Appl. Sci. 2020, 10, 3578. [CrossRef]

11. Osterholz, J.; Heunoske, D.; Horak, J. Experimental characterization of energy transfer from large-diameter kilowatt continuous-wave laser beams to metal samples. J. Laser Appl. 2017, 29, 012011. [CrossRef]

12. Horak, J.; Heunoske, D.; Lueck, M.; Osterholz, J.; Wickert, M. Numerical modeling and characterization of the laser-matter interaction during high-power continuous wave laser perforation of thin metal plates. J. Laser Appl. 2015, 27, S28003. [CrossRef]

13. Xiao, J.; He, H.; Xia, H.; Jia, J. Temperature Flied Simulation on Aluminum Alloy Irradiated by Long Pulsed Laser and Continuous Wave Laser. Chin. J. Lasers 2013, 39, 1103002. [CrossRef]

14. Lee, K.-C.; Baek, W.-K.; Kwon, H.; Shin, W.-S.; Yoh, J.J. Analysis of melt-through process of $1.07 \mu$ m continuous wave high power laser irradiation on metal. J. Mech. Sci. Technol. 2013, 27, 1745-1752. [CrossRef]

15. Khairallah, S.A.; Anderson, A.; Rubenchik, A.M.; Florando, J.; Wu, S.; Lowdermilk, H. Simulation of the main physical processes in remote laser penetration with large laser spot size. AIP Adv. 2015, 5, 047120. [CrossRef]

16. Robin, J.E.; Nordin, P. Reduction of cw laser melt-through times in solid materials by transverse gas flow. J. Appl. Phys. 1975, 46, 2538-2543. [CrossRef]

17. Baek, W.-K.; Lee, K.-C.; An, S.-I.; Shin, W.-S.; Yoh, J.J. Melt-through characteristics in continuous beam irradiation of flying metal samples in flow speeds up to $85 \mathrm{~m} / \mathrm{s}$. Opt. Laser Technol. 2013, 45, 250-255. [CrossRef]

18. Xing, X.; Ma, T.; Wang, R.; Cao, C.; Song, H.; Huang, C. Dynamic rupture of metal sheet subjected to laser irradiation and tangential subsonic airflow. Theor. App. Mech. Lett. 2018, 8, 272-276. [CrossRef]

19. Chippendale, R.D.; Golosnoy, I.O.; Lewin, P.L. Numerical modelling of thermal decomposition processes and associated damage in carbon fibre composites. J. Phys. D Appl. Phys. 2014, 47, 385301. [CrossRef]

20. Gürtler, F.-J.; Karg, M.; Leitz, K.-H.; Schmidt, M. Simulation of Laser Beam Melting of Steel Powders using the Three-Dimensional Volume of Fluid Method. Phys. Procedia 2013, 41, 881-886. [CrossRef]

21. De Rosa, S.; Franco, F. Analytical similitudes applied to thin cylindrical shells. Adv. Aircr. Spacecr. Sci. 2015, 2, 403-425. [CrossRef]

22. Foken, T. 50 Years of the Monin-Obukhov Similarity Theory. Boundary Layer Meteorol. 2006, 119, $431-447$. [CrossRef]

23. Batchelor, G.K. The application of the similarity theory of turbulence to atmospheric diffusion. Q.J.R. Meteorol. Soc. 2010, 76, 133-146.

24. Nemirovskii, Y.V.; Babin, A.I. Coupled Thermoelasticity Problem for Multilayer Composite Shells of Revolution. I. Theoretical Aspects of the Problem. J. Math. Sci. 2018, 229, 211-225. [CrossRef]

25. Bahtui, A.; Eslami, M.R. Generalized coupled thermoelasticity of functionally graded cylindrical shells. Int. J. Numer. Methods Eng. 2007, 69, 676-697. [CrossRef]

26. Tsai, T.-W.; Lee, Y.-M. Analysis of microscale heat transfer and ultrafast thermoelasticity in a multi-layered metal film with nonlinear thermal boundary resistance. Int. J. Heat Mass Transf. 2013, 62, 87-98. [CrossRef]

27. Bergman, T.L.; Lavine, A.S.; Incropera, F.P.; Dewitt, D.P. Fundamentals of Heat and Mass Transfer; John Wiley \& Sons: New York, NY, USA, 2011.

Publisher's Note: MDPI stays neutral with regard to jurisdictional claims in published maps and institutional affiliations. 